Check for updates

Cite this: RSC Adv., 2018, 8, 1973

Received 31st October 2017

Accepted 29th December 2017

DOI: $10.1039 / c 7 r a 11950 j$

rsc.li/rsc-advances

\section{A pillared-layered copper(I) halide-based metal- organic framework exhibiting dual emission, and piezochromic and thermochromic properties with a large temperature-dependent emission red-shift $\uparrow$}

\author{
Bingjing Xin, (DD *ab Jianwei Sang, ${ }^{a}$ Yi Gao, ${ }^{a}$ Guanghua Li, ${ }^{\text {*b }}$ Zhan Shi ${ }^{b}$ \\ and Shouhua Feng ${ }^{b}$
}

We report a new copper halide-based compound $\left[\mathrm{Cu}_{6} \mathrm{I}_{6} \mathrm{Br}_{2} \mathrm{C}_{16} \mathrm{H}_{32} \mathrm{~N}_{4}\right]$ (1) with a 3D 2-fold interpenetrated framework structure. Upon excitation at $290 \mathrm{~nm}$ and $350 \mathrm{~nm}$, compound 1 shows dual emission at ca. $500 \mathrm{~nm}$ and ca. $530 \mathrm{~nm}$. As the temperature decreased from $300 \mathrm{~K}$ down to $6 \mathrm{~K}$, the luminescent properties of compound 1 show large red shifts of $120 \mathrm{~nm}$ and $72 \mathrm{~nm}$, respectively.

\section{Introduction}

Copper(I) halide-based complexes have received much attention because of their excellent luminescent properties and various structures. ${ }^{1}$ Since the structure and luminescent properties of the copper(I) halide-based complex formulated $\left[\mathrm{Cu}_{4} \mathrm{X}_{4} \mathrm{~L}_{4}\right](\mathrm{X}=$ halogen, $\mathrm{L}=$ pyridine) were firstly reported by Hardt and his coworkers in the $1970 \mathrm{~s}^{2}$ a large number of copper halide compounds with interesting photoluminescent properties have been designed and prepared through various effective synthetic strategies. ${ }^{3,4}$ In recent years, several copper halides formulated as $\left[\mathrm{Cu}_{4} \mathrm{I}_{4} \mathrm{~L}_{4}\right](\mathrm{L}=\mathrm{P}, \mathrm{S}, \mathrm{N}$-based ligands) have been reported to show not only excellent luminescent properties but also response characteristics of the luminescence color to thermal or mechanical stimuli., ${ }^{4,5}$ Based on the results of theoretical computation and experimental research, the nature of the thermochromic luminescence or piezochromic luminescence of the copper halide complexes could be associated with two possible causes. One is halide to ligand charge transfer (XLCT) and the other is $\mathrm{Cu}-\mathrm{Cu}$ interactions. ${ }^{\mathbf{4 a - c , 6}}$ Generally, the blue shift is attributed to XLCT excited state and the red shift is attributed to cluster-centered transition. ${ }^{5}$ Although some studies about the thermochromic luminescence or piezochromic luminescence of the copper halide complexes have been performed, the direct evidence to prove that $\mathrm{Cu} \cdots \mathrm{Cu}$ interaction is responsible for thermochromic and piezochromic luminescence is still very limited. ${ }^{\mathbf{4 a , b , 5 a , 7}}$ In this context, it is of significance to synthesize new copper halides with special

ajilin Institute of Chemical Technology, Jilin 132022, P. R. China

${ }^{b}$ State Key Laboratory of Inorganic Synthesis and Preparative Chemistry, College of Chemistry, Jilin University, Changchun 130012, P. R. China

$\dagger$ Electronic supplementary information (ESI) available: The bond lengths, IR spectra and TG curve. CCDC 967744 and 967745. For ESI and crystallographic data in CIF or other electronic format see DOI: $10.1039 / \mathrm{c} 7 \mathrm{ra11950j}$ luminescence behaviours and to clarify the emission mechanism. Herein, we report the synthesis, structure, and photoluminescence properties of a new copper halide-based compound $\left[\mathrm{Cu}_{6} \mathrm{I}_{6} \mathrm{Br}{ }_{2} \mathrm{~L}\right](1)\left(\mathrm{L}=\mathrm{C}_{16} \mathrm{H}_{32} \mathrm{~N}_{4}=1,1^{\prime}\right.$-(butane-1,4diyl)bis(4-aza-1-azonia-bicyclo[2.2.2]octane)), which exhibits interesting luminescence behaviors, such as dual emission, thermochromic luminescence and piezochromic luminescence.

\section{Experimental}

\section{Materials and methods}

All reagents and solvents used were obtained from commercially available sources without further purification. Elemental analyses were performed on a Perkin-Elmer 2400 elemental analyzer. IR spectra were recorded within the $400-4000 \mathrm{~cm}^{-1}$ region on a Nicolet Impact 410 FTIR spectrometer using $\mathrm{KBr}$ pellets. Thermogravimetric experiments were performed with a TGA Q500 V20.10 Build 36 from room temperature to $800^{\circ} \mathrm{C}$ at a heating rate of $10{ }^{\circ} \mathrm{C} \mathrm{min}^{-1}$. X-ray photoelectron spectroscopy (XPS) data were collected on an ESCALAB 250 X-ray photo electron spectroscopy, using $\mathrm{Mg} \mathrm{K} \alpha \mathrm{X}$-ray as the excitation source. X-ray powder diffraction (XRPD) patterns were taken on a Rigaku D/max 2550 X-ray powder diffractometer, with a speed of $1^{\circ} \mathrm{min}^{-1}$. The luminescence spectra were recorded on an Edinburgh Instruments FLS920 spectrofluorimeter from room temperature down to $6 \mathrm{~K}$ at a decreasing rate of $5 \mathrm{~K} \mathrm{~min}^{-1}$ (scan slit, $1.00 \mathrm{~nm}$; fixed/offset slit, $1.00 \mathrm{~nm}$; lamp, Xe900; step, 4.00 $\mathrm{nm})$.

\section{Synthetic procedures}

A mixture of $\mathrm{CuBr}_{2}(1.000 \mathrm{mmol}, 0.223 \mathrm{~g}), \mathrm{HIO}_{4} \cdot 2 \mathrm{H}_{2} \mathrm{O}$ (1.000 mmol, $0.227 \mathrm{~g}$ ), and $\mathrm{NaClO}_{4}(1.000 \mathrm{mmol}, 0.141 \mathrm{~g}$ ), $\mathrm{C}_{6} \mathrm{H}_{12} \mathrm{~N}_{2} \cdot 6 \mathrm{H}_{2} \mathrm{O}$ (1.000 mmol, $0.220 \mathrm{~g}$ ), 1,4-dibromo butane $(0.500 \mathrm{~mL}), \mathrm{H}_{2} \mathrm{O}(5.000 \mathrm{~mL})$ and $\mathrm{HCl}(65 \mu \mathrm{L}$, wt $\%=0.36-0.38)$ 

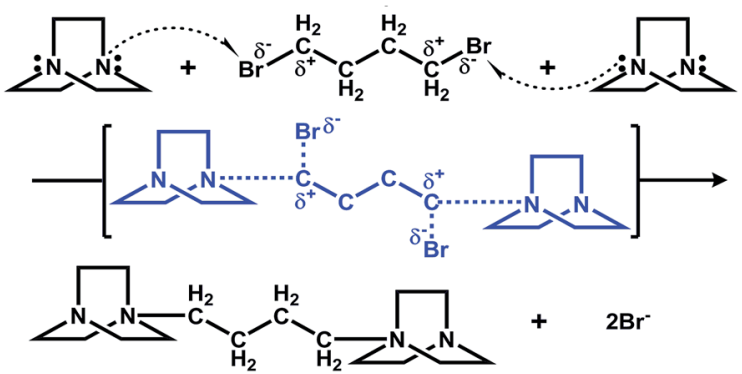

Scheme 1 Mechanism of in situ reaction of DABCO and 1,4-dibromo butane in the synthesis of compound 1 .

was stirred for $24 \mathrm{~h}$ and then $\mathrm{Na}_{2} \mathrm{CO}_{3}(1.785 \mathrm{mmol}, 0.150 \mathrm{~g})$ was added into this solution and stirred for $12 \mathrm{~h}$ in air. This heterogeneous mixture was transferred and sealed in a $15 \mathrm{~mL}$ Teflon-lined steel autoclave. The autoclave was heated in an oven to $160{ }^{\circ} \mathrm{C}$ for 7 days. Then the autoclave was cooled over a period of $24 \mathrm{~h}$ to room temperature, and colorless block crystals were collected by filtration, washed with water and ethanol, and air dried (yield: $46 \%$ based on $\mathrm{CuBr}_{2}$ ). Anal. found: $\mathrm{Cu}, 20.42 ; \mathrm{C}, 11.57 ; \mathrm{N}, 4.55 ; \mathrm{H}, 1.89$. Calcd: $\mathrm{Cu}, 20.50 ; \mathrm{C}$, 11.62; N, 4.52; H, 1.95. IR: 3550 (m), 3447 (s), 3416 (s), $3236(\mathrm{w})$, $3114(\mathrm{~m}), 1638$ (m), 1617 (s), 1457 (m), 1388 (s), 1316 (m), 1165 (w), 1047 (s), $995(\mathrm{~m}), 843(\mathrm{~m}), 787$ (s), $606(\mathrm{~m}), 478(\mathrm{w})$.

\section{In situ reaction}

The results of structural analyses indicate that the structure of the ligands in the final products is different from that of the organic reagents. An in situ organic reaction occurred during the synthesis process according to the experiment results. In fact, several hydrothermal or solvothermal in situ organic reactions have been found in copper halide systems. In our study, the reagents 1,4-dibromo butane and DABCO react with each other to form a cationic ligand in the products, and the mechanism of this in situ alkylation is shown in Scheme 1.

\section{X-ray crystallography}

\section{$\mathrm{X}$-ray photoelectron spectroscopy}

X-ray photoelectron spectroscopy (XPS) experiments for compound 1 have demonstrated the existence of ions $\mathrm{Cu}^{+}, \mathrm{I}^{-}$ and $\mathrm{Br}^{-}$in this compound (Fig. 1).

\section{Results and discussion}

\section{Crystal structure}

Single crystal samples of compound 1 were obtained from hydrothermal reaction of $\mathrm{CuBr}_{2}, \mathrm{HIO}_{4}, \mathrm{DABCO}$ (1,4-diazabicyclo [2.2.2] octane), $\mathrm{NaClO}_{4}$, and 1,4-dibromo butane. Single crystal $\mathrm{X}$-ray diffraction analysis reveals that compound 1 shows a 3D 2fold interpenetrated framework structure (Fig. 2a). Each independent 3D framework is a pillared-layered structure and constructed with copper halide layer and cationic ligand $\mathrm{L}\left(\mathrm{L}=1,1^{\prime}\right.$ (butane-1,4-diyl)bis(4-aza-1-azonia-bicyclo[2.2.2]octane))

(Fig. 2b). The cationic ligand $\mathrm{L}$ was obtained from in situ

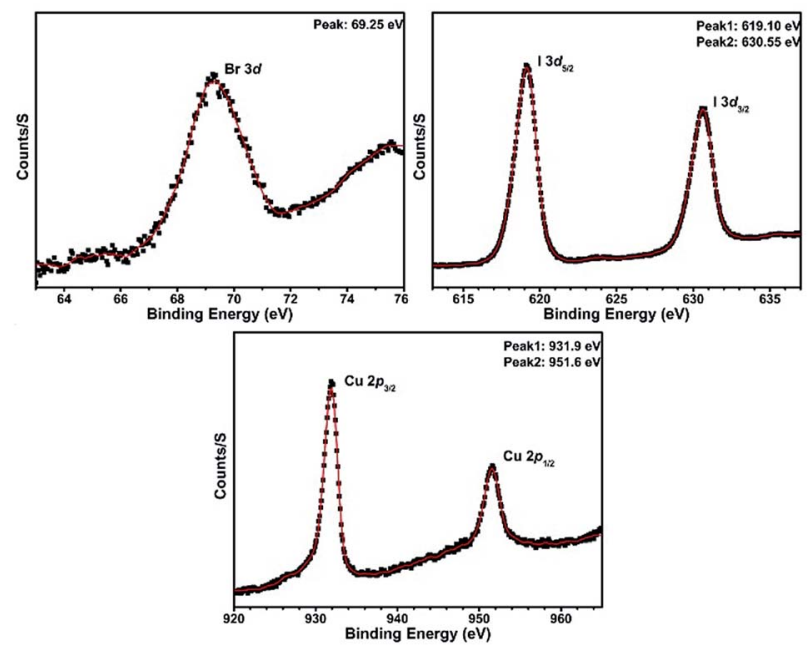

Fig. 1 XPS spectra for compound 1.

alkylation $^{8}$ of the reagents 1,4-dibromo butane and DABCO (Scheme 1). The structure of each infinite copper halide layer with the composition $\left[\mathrm{Cu}_{6} \mathrm{I}_{6} \mathrm{Br}_{2}\right]^{2-}$ is composed by rhombohedral $\mathrm{Cu}_{2} \mathrm{I}_{2}$ dimers through sharing $\mu_{3}-\mathrm{Br}$ and $\mu_{4}$-I (Fig. 2c). There are two types of coordination modes of the rhombohedral $\mathrm{Cu}_{2} \mathrm{I}_{2}$ dimers in the copper halide layer: $\left[\mathrm{Cu}_{2} \mathrm{I}_{2} \mathrm{Br}_{2} \mathrm{~N}_{2}\right]$ SU1 and $\left[\mathrm{Cu}_{2} \mathrm{I}_{4} \mathrm{Br}_{2}\right]$ SU2 (Fig. 2d). The SU1 is coordinated with two bromine atoms and two nitrogen atoms from two different organic ligands and shows a trans-configuration. The SU2 is coordinated with two bromine atoms and two iodine atoms from two SU1 and adopts also a trans-configuration. The distance of $\mathrm{Cu}-\mathrm{I}, \mathrm{Cu}-\mathrm{Br}$, and $\mathrm{Cu}-\mathrm{N}$ in the structure is 2.583(2)-

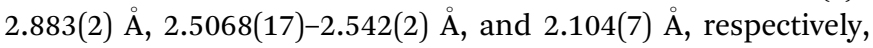
which all falls into the normal range. ${ }^{9}$ In each dimer, there is an attractive interaction between two $\mathrm{Cu}$ centers approaching each other $(\mathrm{Cu}(1)-\mathrm{Cu}(1)=2.617(4) \AA, \mathrm{Cu}(2)-\mathrm{Cu}(2)=2.631(3) \AA$, $\mathrm{Cu}(3)-\mathrm{Cu}(3)=2.626(4) \AA)$. On the other hand, judging from the distances of $\mathrm{Cu}-\mathrm{Cu}(\mathrm{Cu}(1)-\mathrm{Cu}(2)=3.202(9) \AA, \mathrm{Cu}(2)-\mathrm{Cu}(3)=$ $3.211(7) \AA$ ), there is no interaction between the $\mathrm{Cu}$ centers belonging to different dimmers.

\section{Luminescence properties}

The solid state powder samples of compound 1 show fascinating luminescence properties at ambient temperature. Upon excitation at $290 \mathrm{~nm}$ and $350 \mathrm{~nm}$, the sample shows dual emission with a strong high energy (HE) emission band centred at ca. $500 \mathrm{~nm}$ and a weaker low energy (LE) emission band centred at ca. $530 \mathrm{~nm}$ (Fig. 3), respectively. On account of the ligands in the structure of compound $\mathbf{1}$ are saturated amine, the contribution of them to the luminescence should be ignored. Therefore, the luminescence emissions of compound 1 originated mainly from the contribution of the copper halide layers. Based on the reported literature, the emissions at room temperature should be mainly attributed to cluster-centred (CC*) transition with mixed halide-to-metal charge transfer $\left(\mathrm{XMCT}^{*}\right)$ and metal cluster centred $\mathrm{Cu}^{\mathrm{I}} \mathrm{d}^{10} \rightarrow \mathrm{d}^{9} \mathrm{~s}^{1}$ transition (MCC*). ${ }^{1 b, 10}$ It is interesting to point out that most of the copper 
a

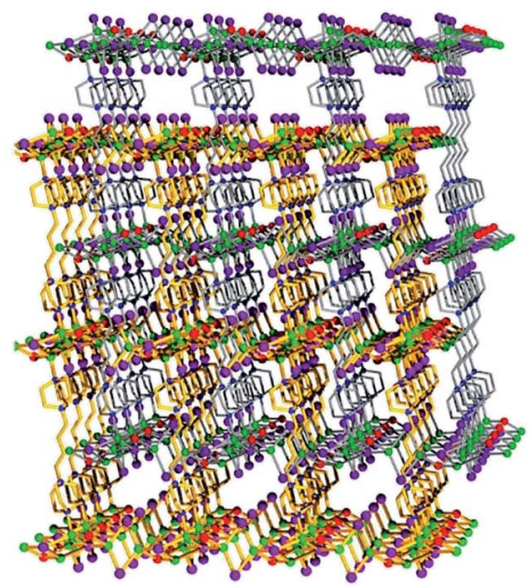

b

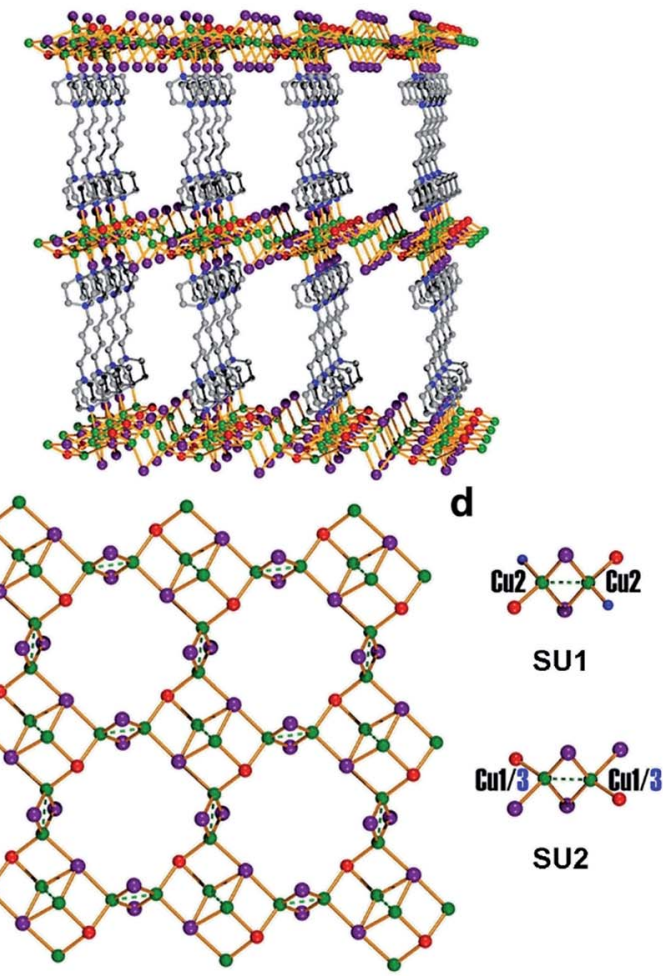

Fig. 2 (a) 2-fold interpenetrated framework structure of compound 1. (b) Independent 3D framework pillared-layered structure of compound 1. (c) The structure of copper halide layer with the composition $\left[\mathrm{Cu}_{6} \mathrm{I}_{6} \mathrm{Br}_{2}\right]^{2-}$. (d) The coordination environment of the $\mathrm{Cu}_{2} \mathrm{I}_{2}$ dimers $\left[\mathrm{Cu}_{2} \mathrm{I}_{2} \mathrm{Br}_{2} \mathrm{~N}_{2}\right]$ (SU1) and $\left[\mathrm{Cu}_{2} \mathrm{I}_{4} \mathrm{Br}_{2}\right]$ (SU2).

halide complexes reported so far exhibit single excitation-single emission characteristics, whereas our sample shows a dual emission characteristic. On the basis of the reported literature and our previous studies on the luminescence of copper halide complexes, ${ }^{11}$ we believe the dual emission behaviour of compound 1 should be attributed to the fact that there are two types of rhombohedral $\mathrm{Cu}_{2} \mathrm{I}_{2}$ dimers (SU1 and SU2) with different coordination environments in the structure of compound 1. Compared with the coordination nitrogen atom, the coordination iodine atom has larger electron density and gas-phase ionization energy which increase the electronaccepting character and lower the excited state energy level of

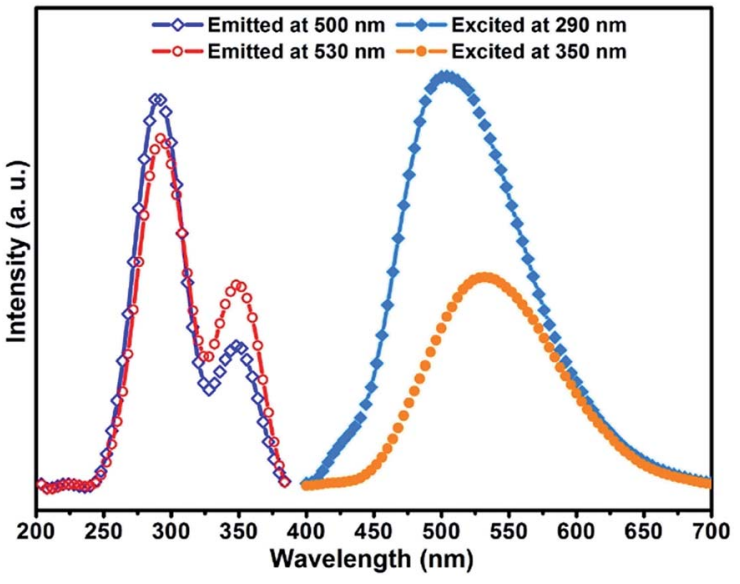

Fig. 3 Excitation and emission spectra for compound 1 at room temperature.

rhombohedral $\mathrm{Cu}_{2} \mathrm{I}_{2}$ dimer. This will cause the excited energy of iodine coordinated dimer SU2 to be lower than that of nitrogen coordinated dimmer SU1. ${ }^{12}$ Recently, Li et al. reported a similar case, and they attributed the dual emission to two different copper cluster luminophores $\left(\mathrm{Cu}_{4} \mathrm{I}_{4}\right.$ and $\left.\mathrm{Cu}_{3} \mathrm{Pz}_{3}\right){ }^{13}$ In order to clarify the luminescence mechanism of compound $\mathbf{1}$, the fluorescence emission and excitation spectra have been investigated at different wavelength. Firstly, monitored at different excitation wavelength from $240 \mathrm{~nm}$ to $390 \mathrm{~nm}$, the emission band centred at $500 \mathrm{~nm}\left(\lambda_{\mathrm{ex}} \leq 290 \mathrm{~nm}\right)$ and $530 \mathrm{~nm}\left(\lambda_{\mathrm{ex}}>290 \mathrm{~nm}\right)$ (Fig. S1 in ESI $\dagger$ ). The experiment results show that compound 1 has dual emission properties. Then, when emission wavelength from $400 \mathrm{~nm}$ to $680 \mathrm{~nm}$ was utilized to monitor the excitation spectra of compound $\mathbf{1}$, the results show that the excitation spectra both consist of two excitation bonds centred at $290 \mathrm{~nm}$ and $350 \mathrm{~nm}$. However, the relative intensity radio of the excitation peak at $290 \mathrm{~nm}$ to the peak at $350 \mathrm{~nm}$ changed from 2.71 (monitored at $500 \mathrm{~nm}$ ) down to 1.66 (monitored at $530 \mathrm{~nm}$ ) (Fig. S2 in ESI $\dagger$ ). Based on the aforementioned, it is easy to see that both of the two structure units SU1 and SU2 contribute to this dual emission phenomenon of the compound. Compared with SU2, which prefers to affect emission at $530 \mathrm{~nm}$, SU1 predominantly contributes to emission at $500 \mathrm{~nm}$.

Moreover, it is interesting to note that the luminescence properties of this compound are sensitive to pressure. ${ }^{14}$ When the solid state powder sample of compound $\mathbf{1}$ is pressed into a thick piece under $25 \mathrm{MPa}$ pressure, its emission spectra are slightly red-shifted (Fig. 4). Excited at $290 \mathrm{~nm}$, the emission peak of this compound is red shifted from $500 \mathrm{~nm}$ to $524 \mathrm{~nm}$, and correspondingly from $530 \mathrm{~nm}$ to $556 \mathrm{~nm}$ upon excited at $350 \mathrm{~nm}$. Excited at $290 \mathrm{~nm}$ and $350 \mathrm{~nm}$, the corresponding red shift of the emission peak is about $25 \mathrm{~nm}$, respectively. However, the XRD data of the compound before and after compressing are consistent (see Fig. 5), which means that the structure of the compound did not change after it was compressed. Such results indicate this red shift phenomenon might result from the weak bond contraction of the copper halide layer which is caused by pressing. 


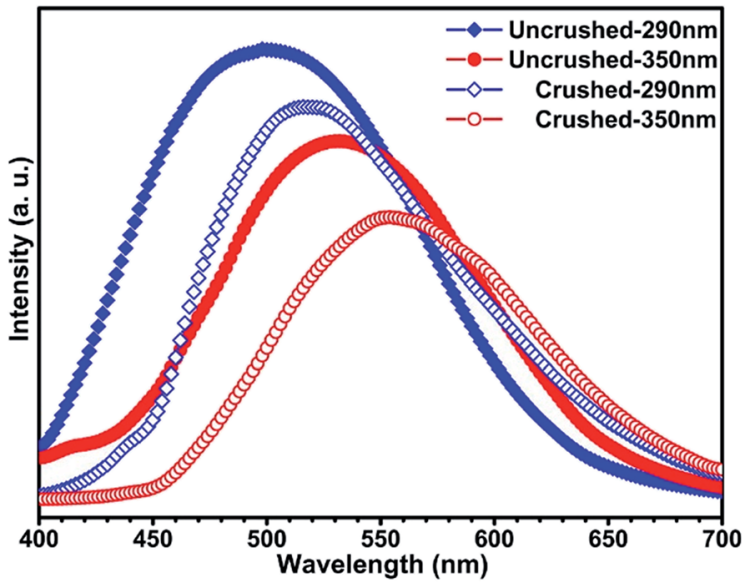

Fig. 4 Emission spectra for compound 1 before and after being crushed upon excitation at $290 \mathrm{~nm}$ and $350 \mathrm{~nm}$, respectively.

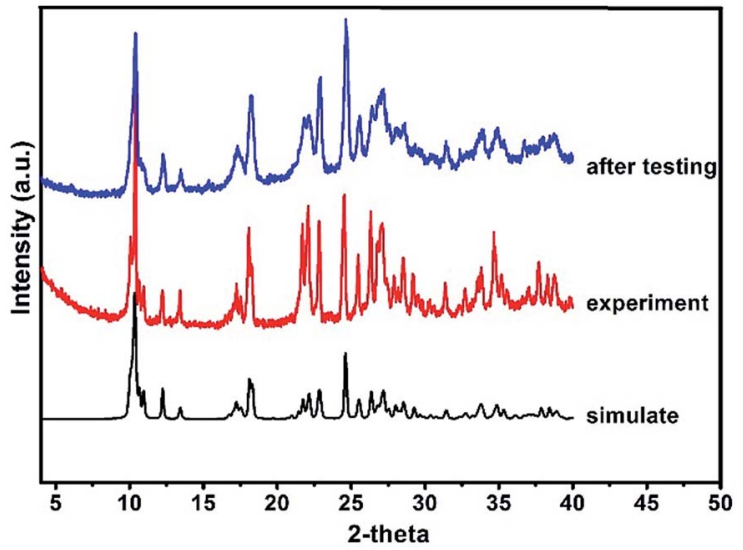

Fig. 5 X-Ray powder diffraction patterns for compound 1.

More interestingly, the luminescence properties of compound $\mathbf{1}$ are not only responsive to pressure, but also show a more sensitive response to temperature. Compound 1 exhibits luminescence with various colors at different temperature and the color change of luminescence under UV illumination can be easily observed by naked eyes (illustration in Fig. 6). Upon excitation at $290 \mathrm{~nm}$, the maxima emission peak of compound 1 shifted from $500 \mathrm{~nm}$ to $620 \mathrm{~nm}$ as the temperature decreased from $300 \mathrm{~K}$ down to $6 \mathrm{~K}$, and the red shift of the emission peak is about $120 \mathrm{~nm}$ (Fig. 6, Table 2). The luminescence colors at $300 \mathrm{~K}$ and $6 \mathrm{~K}$ can be quantified by the CIE (Commission International de L'Eclairage) 1931 chromaticity coordinates, and the values are $x=0.16, y=0.32$ and $x=0.47, y=0.42$, respectively. Under excitation at $350 \mathrm{~nm}$, the luminescence of compound 1 showed similar change trend in the luminescence excited at $290 \mathrm{~nm}$. The maxima emission peak in emission spectra shifted from $530 \mathrm{~nm}$ to $602 \mathrm{~nm}$, and the shift value of the emission peak is about $72 \mathrm{~nm}$ (Fig. 6, Table 2). The CIE values of luminescence colors at $300 \mathrm{~K}$ and $6 \mathrm{~K}$ are $x=0.27, y=0.46$ and $x=0.45, y=$ 0.46 , respectively. At present, several copper halide compounds with thermochromic luminescence properties have been
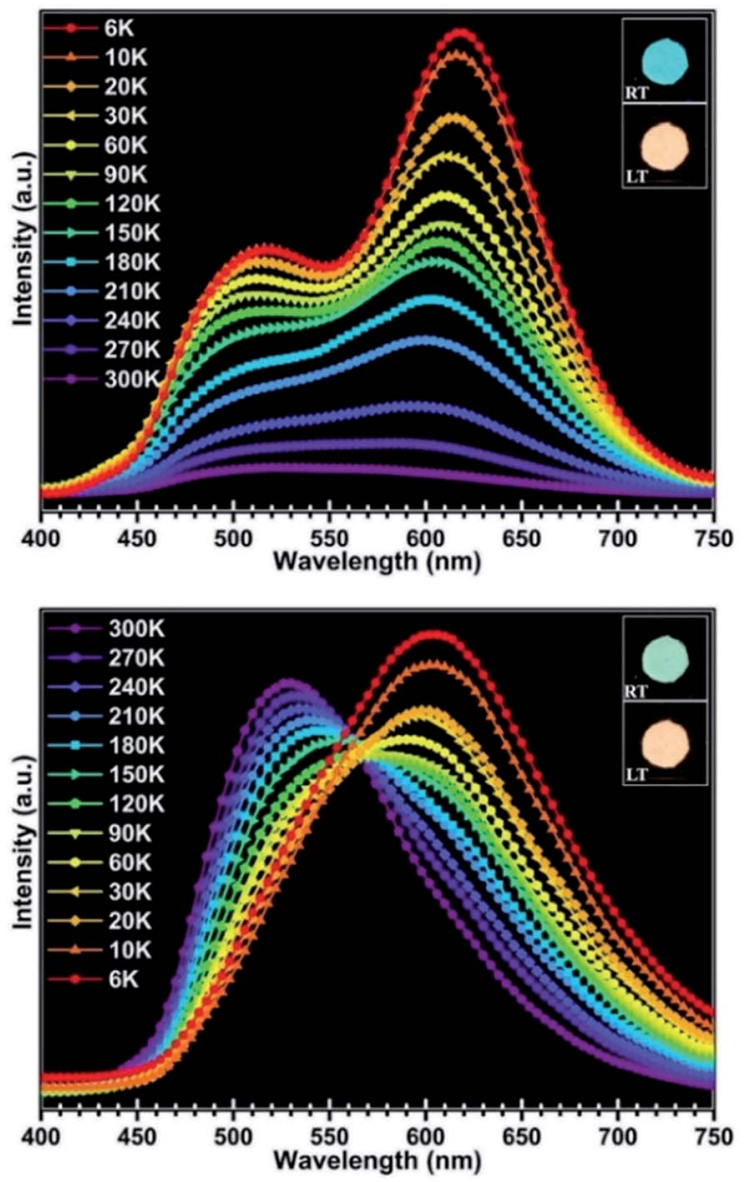

Fig. 6 Solid-state luminescence spectra of compound 1 at $290 \mathrm{~nm}$ (up) and at $350 \mathrm{~nm}$ (down) between $300 \mathrm{~K}$ and $6 \mathrm{~K}$ (RT: room temperature; LT: lower temperature).

reported, ${ }^{15}$ whereas in this work, the red-shift value is $120 \mathrm{~nm}$. The orange luminescence of compound $\mathbf{1}$ could be easily reverted to blue-green and green, while the temperature changed back to $298 \mathrm{~K}$. This indicates that compound 1 exhibits excellent reversibility during temperature detecting process.

To investigate the relationship between the luminescence behaviour and the crystal structure, we collected the crystal data for compound 1 at $293 \mathrm{~K}$ and $113 \mathrm{~K}$ (see Table 1 ). The crystal data reveal that no phase transition occurs in this compound with lowering the temperature. The main difference between the crystal structures is that bonds and angles show some variation at different temperature, wherein $\mathrm{Cu}-\mathrm{Cu}$ distances in the structure become shorter with decreasing temperature (Table 3). Compared with $\mathrm{Cu}-\mathrm{Cu}$ bond lengths, the other bond lengths such as $\mathrm{Cu}-\mathrm{X}, \mathrm{Cu}-\mathrm{N}, \mathrm{C}-\mathrm{C}$ and $\mathrm{C}-\mathrm{N}$ of compound 1 show smaller changes (see Table $\mathrm{S} 1$ in ESI $\dagger$ ). Because the emission properties of compound $\mathbf{1}$ are related with halide-to-metal charge transfer (XMCT) and metal cluster centred $\mathrm{Cu}^{\mathrm{I}} \mathrm{d}^{10} \rightarrow$ $\mathrm{d}^{9} \mathrm{~s}^{1}$ transition (MCC ${ }^{*}$ ) which originate from the copper halide layer, the luminescent changes of this compound should be attributable to the length changes of $\mathrm{Cu}-\mathrm{X}$ and $\mathrm{Cu}-\mathrm{Cu}$. However, compared with the former one, the latter is more evident. Consequently, thermochromism luminescence of 
Table 1 Crystal data and structure refinement for compound 1

\begin{tabular}{|c|c|c|}
\hline Parameter & $293 \mathrm{~K}$ & $113 \mathrm{~K}$ \\
\hline Formula & $\mathrm{C}_{16} \mathrm{H}_{32} \mathrm{~N}_{4} \mathrm{Cu}_{6} \mathrm{I}_{6} \mathrm{Br}_{2}$ & $\mathrm{C}_{16} \mathrm{H}_{32} \mathrm{~N}_{4} \mathrm{Cu}_{6} \mathrm{I}_{6} \mathrm{Br}_{2}$ \\
\hline Formula weight & 1582.92 & 1582.92 \\
\hline Crystal system & Triclinic & Triclinic \\
\hline Space group & $P \overline{1}$ & $P \overline{1}$ \\
\hline$a, \AA$ & $9.856(2)$ & $9.7150(19)$ \\
\hline$b, \AA$ & $9.951(2)$ & $9.887(2)$ \\
\hline$c, \AA$ & $10.625(2)$ & $10.541(2)$ \\
\hline$\alpha,{ }^{\circ}$ & $62.77(3)$ & $62.33(3)$ \\
\hline$\beta, \circ$ & $64.90(3)$ & $66.13(3)$ \\
\hline$\gamma, \circ$ & $84.22(3)$ & $84.03(3)$ \\
\hline$V, \AA^{3}$ & $833.4(3)$ & $815.6(3)$ \\
\hline$Z$ & 1 & 1 \\
\hline$D_{\text {calc }}, \mathrm{g} \mathrm{cm}^{-3}$ & 3.154 & 3.223 \\
\hline Goof & 1.086 & 1.102 \\
\hline Final $R$ indices $[I>2 \sigma(I)]^{a, b}$ & $\begin{array}{l}R_{1}=0.0545 \\
w R_{2}=0.1433\end{array}$ & $\begin{array}{l}R_{1}=0.0463 \\
\mathrm{w} R_{2}=0.1175\end{array}$ \\
\hline$R$ indices (all data) & $\begin{array}{l}R_{1}=0.0696 \\
w R_{2}=0.1528\end{array}$ & $\begin{array}{l}R_{1}=0.0529 \\
\mathrm{w} R_{2}=0.1206\end{array}$ \\
\hline
\end{tabular}

Table 2 Solid state emission for 1 was recorded from room temperature down to $6 \mathrm{~K}$ under excitation at $290 \mathrm{~nm}$ and $350 \mathrm{~nm}$ respectively

\begin{tabular}{|c|c|c|c|}
\hline \multirow[b]{2}{*}{$\lambda_{\mathrm{ex}}(\mathrm{nm})$} & \multirow{2}{*}{$\frac{300 \mathrm{~K}}{\lambda_{\mathrm{em}}(\mathrm{nm})}$} & $6 \mathrm{~K}$ & \multirow[b]{2}{*}{ Shift (nm) } \\
\hline & & $\lambda_{\mathrm{em}}(\mathrm{nm})$ & \\
\hline 290 & 500 & 620 & 120 \\
\hline 350 & 530 & 602 & 72 \\
\hline
\end{tabular}

Table $3 \mathrm{Cu} \cdot \mathrm{Cu}$ distances $[\AA]$ in compound 1 at two different temperatures

\begin{tabular}{llll}
\hline Bonds & $293 \mathrm{~K}$ & $113 \mathrm{~K}$ & $D$-value \\
\hline $\mathrm{Cu}(1) \cdots \mathrm{Cu}(1)$ & $2.617(4)$ & $2.602(3)$ & 0.015 \\
$\mathrm{Cu}(2) \cdots \mathrm{Cu}(2)$ & $2.631(3)$ & $2.601(2)$ & 0.030 \\
$\mathrm{Cu}(3) \cdots \mathrm{Cu}(3)$ & $2.626(4)$ & $2.598(3)$ & 0.028
\end{tabular}

compound $\mathbf{1}$ is predominantly contributed to the cuprophilic interactions. When the temperature decreases, the bond length of $\mathrm{Cu}-\mathrm{Cu}$ becomes shorter, leading to obvious bonding characteristics, which give rise to the lowering of the corresponding energy level. As a result, the emission spectra of this compound will be red-shifted. Simultaneously, the value of red shift excited at $290 \mathrm{~nm}$ is larger than that for $350 \mathrm{~nm}$. This is because in structure units SU1 and SU2, the magnitudes of bond length change of $\mathrm{Cu}-\mathrm{Cu}$ with decreasing temperature are different. According to the data shown in Table 3, the magnitude of changes in SU1 is larger than that in SU2. At room temperature, SU1 plays an important role for excitation at $290 \mathrm{~nm}$ and SU2 for $350 \mathrm{~nm}$. Therefore, it could be revealed that the difference of red-shift value between excitation at $290 \mathrm{~nm}$ and $350 \mathrm{~nm}$ originated from the fact that the magnitude of changes for SU1 is larger than that for SU2.

\section{Conclusions}

In summary, a new copper halide compound exhibiting interesting luminescence behaviours, such as dual emission, thermochromic luminescence and piezochromic luminescence, has been prepared through hydrothermal synthesis. In terms of the thermochromic luminescence properties, this compound displays a larger red-shift. Also, crystal structure data demonstrate that the temperature dependent variation of $\mathrm{Cu} \cdots \mathrm{Cu}$ distance is responsible for the luminescence thermochromism of copper halide compounds. Finally, this study provides strong data support for investigations of the temperature dependent property of this kind of compound.

\section{Conflicts of interest}

There are no conflicts to declare.

\section{Acknowledgements}

This work was supported by the Foundation of the National Natural Science Foundation of China (No. 21371069, 21241010), Specialized Research Fund for the Doctoral Program of Higher Education (No. 20110061110015), National High Technology Research and Develop Program (863 program) of China (No. 2013AA031702) and Fund for Distinguished Young Scholars of Jilin City (No. 20156419).

\section{References}

1 (a) N. Armaroli, G. Accorsi, F. Cardinali and A. Listorti, Top. Curr. Chem., 2007, 280, 69; (b) P. C. Ford, E. Cariati and J. Bourassa, Chem. Rev., 1999, 99, 3625; (c) V. W. W. Yam and K. K. W. Lo, Chem. Soc. Rev., 1999, 28, 323; (d) A. Barbieri, G. Accorsi and N. Armaroli, Chem. Commun., 2008, 2185; (e) E. Cariati, D. Roberto, R. Ugo, P. C. Ford, S. Galli and A. Sironi, Inorg. Chem., 2005, 44, 4077.

2 (a) H. D. Hardt and H. Gechnizdjani, Z. Anorg. Allg. Chem., 1973, 397, 23; (b) H. D. Hardt and A. Pierre, Z. Anorg. Allg. Chem., 1973, 402, 107; (c) H. D. Hardt and H. J. Stoll, $Z$. Anorg. Allg. Chem., 1981, 480, 193.

3 (a) R. Peng, M. Li and D. Li, Coord. Chem. Rev., 2010, 254, 1; (b) S. Hu and M. L. Tong, Dalton Trans., 2005, 1165.

4 (a) T. H. Kim, Y. W. Shin, J. H. Jung, J. S. Kim and J. Kim, Angew. Chem., Int. Ed., 2008, 47, 685; (b) D. Braga, L. Maini, P. P. Mazzeo and B. Ventura, Chem.-Eur. J., 2010, 16, 1553; (c) C. d. Tard, S. Perruchas, S. b. Maron, X. F. L. Goff, F. o. Guillen, A. Garcia, J. Vigneron, A. Etcheberry, T. Gacoin and J. P. Boilot, Chem. Mater., 2008, 20, 7010; (d) P. C. Ford, Coord. Chem. Rev., 1994, 132, 129; (e) H. Kitagawa, Y. Ozawa and K. Toriumi, Chem. Commun., 2010, 46, 6302; (f) X. C. Shan, F. L. Jiang, D. Q. Yuan, H. B. Zhang, M. Y. Wu, L. Chen, J. Wei, S. Q. Zhang, J. Pan and M. C. Hong, Chem. Sci., 2013, 4, 1484; $(g)$ S. Perruchas, 
X. F. L. Goff, S. Maron, I. Maurin, F. Guillen, A. Garcia, T. Gacoin and J. P. Boilot, J. Am. Chem. Soc., 2010, 132, 10967; (h) K. M. Henline, C. Wang and R. D. Pike, Cryst. Growth Des., 2014, 14, 1449; (i) X. Shan, H. Zhang, L. Chen, M. Wu, F. Jiang and M. Hong, Cryst. Growth Des., 2013, 13, 1377.

5 (a) S. Perruchas, X. F. L. Goff, S. Maron, I. Maurin, F. Guillen, A. Garcia, T. Gacoin and J. P. Boilot, J. Am. Chem. Soc., 2010, 132, 10967; (b) S. Perruchas, C. Tard, X. F. L. Goff, A. Fargues, A. Garcia, S. Kahlal, J. Y. Saillard, T. Gacoin and J. P. Boilot, Inorg. Chem., 2011, 50, 10682; (c) I. Roppolo, E. Celasco, A. Fargues, A. Garcia, A. e. Revaux, G. e. Dantelle, F. Maroun, T. Gacoin, J. P. Boilot, M. Sangermanoa and S. Perruchas, J. Mater. Chem., 2011, 21, 19106; (d) S. Perruchas, N. Desboeufs, S. Maron, X. F. L. Goff, A. Fargues, A. Garcia, T. Gacoin and J. P. Boilot, Inorg. Chem., 2012, 51, 794; (e) Q. Benito, X. F. L. Goff, S. Maron, A. Fargues, A. Garia, C. Martineau, F. Taulelle, S. Kahlal, T. Gacion, J. P. Boilot and S. Perruchas, J. Am. Chem. Soc., 2014, 136, 11311.

6 (a) F. Gong, Q. Wang, J. Chen, Z. Yang, M. Liu, S. Li and G. Yang, Inorg. Chem., 2010, 49, 1658; (b) J. X. Zhang, J. He, Y. G. Yin, M.-H. Hu, D. Li and X. C. Huang, Inorg. Chem., 2008, 47, 3471; (c) C.-M. Che, Z. Mao, V. M. Miskowski, M. C. Tse, C. K. Chan, K. K. Cheung, D. L. Phillips and K. H. Leung, Angew. Chem., 2000, 112, 4250; (d) C. M. Che, Z. Mao, V. M. Miskowski, M. C. Tse, C. K. Chan, K. K. Cheung, D. L. Phillips and K. H. Leung, Angew. Chem., 2000, 112, 4084.

7 E. Cariati, X. Bu and P. C. Ford, Chem. Mater., 2000, 12, 3385. 8 (a) M. Li, Z. Li and D. Li, Chem. Commun., 2008, 3390; (b) J. K. Cheng, Y. B. Chen, L. Wu, J. Zhang, Y. H. Wen, Z. J. Li and Y. G. Yao, Inorg. Chem., 2005, 44, 3386; (c) J. P. Zhang, Y. Y. Lin, X. C. Huang and X. M. Chen, J. Am. Chem. Soc., 2005, 127, 5495; (d) J. K. Cheng, Y. G. Yao, J. Zhang, Z. J. Li, Z. W. Cai, X. Y. Zhang, Z. N. Chen, Y. B. Chen, Y. Kang, Y. Y. Qin and Y. H. Wen, J. Am. Chem. Soc., 2004, 126, 7796; (e) J. Y. Lu and A. M. Babb, Inorg. Chem., 2002, 41, 1339; (f) J. J. Hou, S. L. Li, C. R. Li and X. M. Zhang, Dalton Trans., 2010, 39, 2701.
9 (a) C. M. Jin, Z. Zhu, M. X. Yao and X. G. Meng, CrystEngComm, 2010, 12, 358; (b) W. F. Fu, X. Gan, C. M. Che, Q. Y. Cao, Z. Y. Zhou and N. N. Y. Zhu, Chem.Eur. J., 2004, 10, 2228; (c) Z. G. Zhao, J. Zhang, X. Y. Wu, Q. G. Zhai, L. J. Chen, S. M. Chen, Y. M. Xie and C. Z. Lu, CrystEngComm, 2008, 10, 273.

10 (a) X. Xue, X. S. Wang, R. G. Xiong, X. Z. You, B. F. Abrahams, C. M. Che and H. X. Ju, Angew. Chem., Int. Ed., 2002, 41, 2944; (b) M. Vitale and P. C. Ford, Coord. Chem. Rev., 2001, 219; (c) Y. Kang, F. Wang, J. Zhang and X. Bu, J. Am. Chem. Soc., 2012, 134, 17881.

11 (a) B. Xin, Y. Li, G. Zeng, Y. Peng, G. Li, Z. Shi and S. Feng, Z. Anorg. Allg. Chem., 2012, 639, 611; (b) G. Zeng, S. Xing, X. Wang, Y. Yang, Y. Xiao, Z. Li, G. Li, Z. Shi and S. Feng, CrystEngComm, 2016, 18, 4336; (c) G. Zeng, S. Xing, X. Han, B. Xin, Y. Yang, X. Wang, G. Li, Z. Shi and S. Feng, $R S C$ Adv., 2015, 5, 40792.

12 (a) K. Tsuge, Y. Chishina, H. Hashiguchi, Y. Sasaki, M. Kato, S. Ishizaka and N. Kitamura, Coord. Chem. Rev., 2016, 306, 636; (b) J. Huang, L. Huo, Z. Deng and S. Gao, Polyhedron, 2017, 122, 46; (c) J. P. Safko, J. E. Kuperstock, S. M. McCullough, A. M. Noviello, X. Li, J. P. Killarney, C. Murphy, H. H. Patterson, C. A. Baysec and R. D. Pike, Dalton Trans., 2012, 41, 11663.

13 S. Z. Zhan, M. Li, X. P. Zhou, J. H. Wang, J. R. Yang and D. Li, Chem. Commun., 2011, 47, 12441.

14 (a) J. Kunzelman, M. Kinami, B. R. Crenshaw, J. D. Protasiewicz and C. Weder, Adv. Mater., 2008, 20, 119; (b) A. L. Balch, Angew. Chem., Int. Ed., 2009, 48, 2641; (c) G. Q. Zhang, J. W. Lu, M. Sabat and C. L. Fraser, J. Am. Chem. Soc., 2010, 132, 2160; (d) D. P. Yan, J. Lu, J. Ma, S. H. Qin, M. Wei, D. G. Evans and X. Duan, Angew. Chem., Int. Ed., 2011, 50, 7037.

15 (a) Q. Benito, X. F. L. Goff, S. Maron, A. Fargues, A. Garia, C. Martineau, F. Taulelle, S. Kahlal, T. Gacion, J. P. Boilot and S. Perruchas, J. Am. Chem. Soc., 2014, 136, 11311; (b) Q. Benito, B. Baptiste, A. Polian, L. Delbes, L. Martinelli, T. Gacoin, J. Boilot and S. Perruchas, Inorg. Chem., 2015, 54, 9821; (c) D. Sun, S. Yuan, H. Wang, H. F. Lu, S. Y. Feng and D. F. Sun, Chem. Commun., 2013, 49, 6152. 